\title{
Measurement and Computation of Movement of Bromide Ions and Carbofuran in Ridged Humic-Sandy Soil
}

\author{
Minze Leistra $\cdot$ Jos J. T. I. Boesten
}

Received: 1 May 2009/Accepted: 23 November 2009/Published online: 30 December 2009

(c) The Author(s) 2009. This article is published with open access at Springerlink.com

\begin{abstract}
Water flow and pesticide transport in the soil of fields with ridges and furrows may be more complex than in the soil of more level fields. Prior to crop emergence, the tracer bromide ion and the insecticide carbofuran were sprayed on the humic-sandy soil of a potato field with ridges and furrows. Rainfall was supplemented by sprinkler irrigation. The distribution of the substances in the soil profile of the ridges and furrows was measured on three dates in the potato growing season. Separate ridge and furrow systems were simulated by using the pesticide emission assessment at regional and local scales (PEARL) model for pesticide behavior in soil-plant systems. The substances travelled deeper in the furrow soil than in the ridge soil, because of runoff from the ridges to the furrows. At 19 days after application, the peak of the bromide distribution was measured to be in the $0.1-0.2 \mathrm{~m}$ layer of the ridges, while it was in the $0.3-0.5 \mathrm{~m}$ layer of the furrows. After 65 days, the peak of the carbofuran distribution in the ridge soil was still in the $0.1 \mathrm{~m}$ top layer, while the pesticide was rather evenly distributed in the top $0.6 \mathrm{~m}$ of the furrow soil. The wide ranges in concentration measured with depth showed that preferential water flow and substance transport occurred in the sandy soil. Part of the bromide ion distribution was measured to move faster in soil than the computed wave. The runoff of water and pesticide from the ridges to the furrows, and the thinner root zone in the furrows, are expected to increase the risk
\end{abstract}

M. Leistra $(\bowtie)$ J. J. T. I. Boesten

Alterra, Wageningen University and Research Centre, Post

Office Box 47, 6700 AA Wageningen, The Netherlands

e-mail: Minze.Leistra@wur.nl

J. J. T. I. Boesten

e-mail: Jos.Boesten@wur.nl of leaching to groundwater in ridged fields, in comparison with more level fields.

The registration procedures for agricultural pesticides include an assessment of the risk of leaching to groundwater. Nearly all field experiments on the movement of pesticides in soil have been carried out on fields with a comparatively level soil surface. The computation models recommended by FOCUS (2000) as a tool in the evaluation of the risk of leaching of pesticides to groundwater are pesticide emission assessment at regional and local scales (PEARL), pesticide leaching model (PELMO), and pesticide root zone model (PRZM). Several agricultural scenarios are defined based on representative European situations, for use in risk evaluations. In all models and scenarios, the soil surface in the field is assumed to be level. In practice, however, various crops (potato, for example) are grown on ridges, which raises the question of the extent to which the risk of pesticide leaching to groundwater is affected by the ridge-furrow system in the field.

Potatoes are a main crop in the temperate regions of Europe and North America. The acreage in The Netherlands is $1.5 \times 10^{5}$ ha (CBS 2009) and in the European Union it is $2.1 \times 10^{6}$ ha (Eurostat 2009). The main uses in The Netherlands are direct consumption, starch production, and (international) seed tuber trade. Almost all potato crops are grown on ridges, mainly to prevent water logging in rainy periods, to allow expansion of the tubers, and to facilitate mechanical harvesting. The use of pesticides on potato crops (herbicides, insecticides, and fungicides) is rather high as compared with various other crops. Potato is an important crop on sandy soils in areas where phreatic groundwater is pumped for drinking water supply (e.g., Wyman et al. 1985; Robinson 1999). The crop often receives supplementary 
sprinkler irrigation when needed. Some other crops can also be grown on ridges, e.g., corn in the USA (Butters et al. 2000; Waddell and Weil 2006). Various horticultural crops are grown on elevated beds, with furrows in between.

A ridged soil surface can increase heterogeneity in water infiltration into the soil surface and of water flow through the soil profile (Saffigna et al. 1976; Robinson 1999; Starr et al. 2005; Cooley et al. 2007). Water from rainfall and sprinkler irrigation can flow off the ridges into the furrows, where it infiltrates. As the crop develops, it intercepts more precipitation, increasing the extent of localized flow through the canopy (along stems and leaves) and local infiltration into the soil, both in the ridges and in the furrows. A study on the movement of the nematicide aldicarb and its bioactive oxidation products in the soil of ridged potato fields (Smelt et al. 1981) found that, in a humicsandy soil, the substances penetrated deeper below the furrows than below the ridges. This was ascribed to rainwater flowing down the ridges to the furrows. When humicsandy topsoils dry out they may become water repellent (Robinson 1999; Dekker et al. 1999), thus impeding water infiltration and promoting surface flow to the furrows.

In the field experiment described in this study, bromide ion (as a tracer for water flow) and the example pesticide carbofuran (2,3-dihydro-2,2-dimethyl-7-benzofuranyl methylcarbamate) were sprayed on the soil of a ridged potato field. The distribution of the substances in the humic-sandy soil profile was measured on three dates in the growing season. Computations on water flow and substance behavior in soil were carried out by using the PEARL model for pesticide behavior in soil-plant systems (Tiktak et al. 2000; Leistra et al. 2001). Separate ridge and furrow systems were distinguished in the potato field. The computed and measured substance distributions in soil were compared and the differences evaluated.

\section{Procedures}

\section{Experimental}

The field experiment, with application of bromide ion (as water tracer) and carbofuran (as example pesticide), was carried out on an arable field with humic-sandy soil near Roswinkel (Province of Drenthe, The Netherlands). The soil profile consisted of a humic fine-sandy plow layer $(0.3 \mathrm{~m}$ thick), overlying a fine-sand subsoil in which the organic matter content decreased with depth (Table 1). The Food and Agriculture Organization (FAO) soil classification is gleyic podzol (FAO 1988). The groundwater table fluctuated around $1 \mathrm{~m}$ depth (Leistra and Boesten 2008). Potatoes were planted on the field on 20 April 2000, in rows $0.75 \mathrm{~m}$ apart. On 8 May, the rows of potatoes were hilled up with soil from the furrows to form ridges $0.20 \mathrm{~m}$ high. On 10 May, carbofuran (formulated as Curaterr liquid, $200 \mathrm{~g}$ carbofuran per 1; Bayer) was sprayed on the soil surface (with ridges and furrows) from a tractor-mounted boom sprayer. The dosage of $4.63 \mathrm{~kg}$ carbofuran per ha was applied in 6171 spray liquid per ha. Subsequently, $\mathrm{KBr}$ (>99\%; Fluka) solution was sprayed at a dosage corresponding to $64.7 \mathrm{~kg}$ bromide ion per ha, also in $617 \mathrm{l} \mathrm{ha}^{-1}$. The size of the sprayed area was $21 \mathrm{~m}$ (boom width) $\times 100 \mathrm{~m}$. Potato plants emerged around 22 May 2000. The canopy cover increased roughly linearly, with almost full cover achieved on 10 July. Rooting depth can be assumed to have been restricted to the top $0.5 \mathrm{~m}$ of the soil profile, because below this was a dense sand layer. The potatoes were harvested by the end of November 2000, but the leaves died off well before then. In the next year (2001), the field lay fallow.

Natural rainfall was supplemented by sprinkler irrigation (in May and June 2000), and the total amount of water was measured with rain gages (Leistra and Boesten 2008). The daily values of reference crop evaporation were taken to be the average of the values calculated (KNMI 2000) for the weather stations at the nearest airports (Eelde and Hoogeveen). This evaporation was calculated by Makkink's method (Feddes 1987). The cumulative amounts of rainfall plus irrigation and of reference crop evaporation are given in Fig. 1. In the period from 10 May to 24 June the field was sprinkler-irrigated eight times, giving a total of $124 \mathrm{~mm}$. Rainfall in the period 10 May to 30 September was $389 \mathrm{~mm}$. Fig. 1 shows that a substantial amount of water $(513 \mathrm{~mm}$ in total) fell on the field. Cumulative reference crop evaporation was $354 \mathrm{~mm}$. The air temperatures were measured at the field. The depth of the groundwater table was measured via six filter tubes, installed before the substances were sprayed.

On three dates in the potato growing season (29 May, 13 July, and 18 September 2000), soil samples were taken with coring tubes (length $1.0 \mathrm{~m}$, diameter $0.094 \mathrm{~m}$ ).

Table 1 Characteristics of the soil of the Roswinkel experimental field

\begin{tabular}{llllll}
\hline Soil layer $(\mathrm{m})$ & Sand $(>50 \mu \mathrm{m} ; \%)$ & Silt $(2-50 \mu \mathrm{m} ; \%)$ & Clay $(<2 \mu \mathrm{m} ; \%)$ & Organic matter $(\%)$ & 4.3 \\
\hline $0-0.3$ & 87.9 & 8.5 & 3.6 & 1.5 & 4.5 \\
$0.3-0.5$ & 92.5 & 5.0 & 2.5 & 0.4 & 4.8 \\
$0.5-1.0$ & 95.3 & 2.7 & 2.0 & 5.0 \\
\hline
\end{tabular}

Soil layers for the level field. Sand, silt, and clay are given as percentages of the mineral fraction 


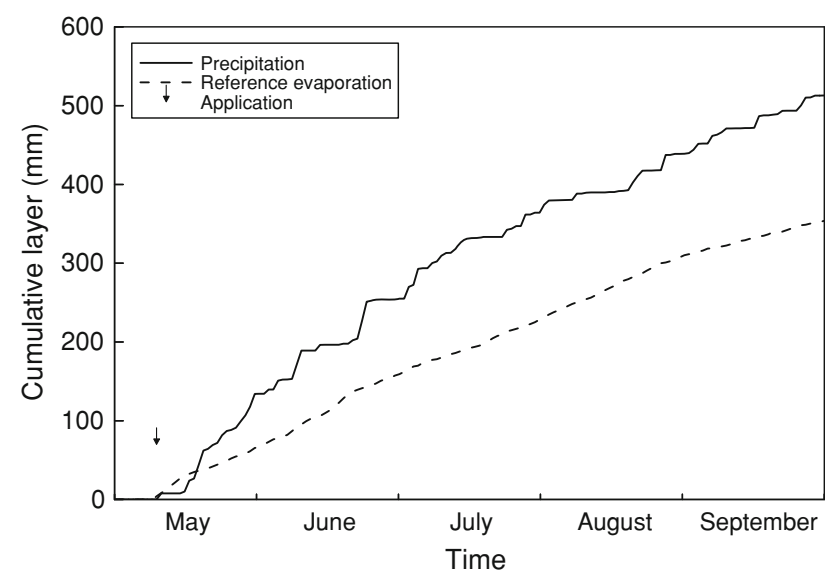

Fig. 1 Cumulative precipitation (rainfall plus sprinkler irrigation) and cumulative reference crop evaporation for the field experiment

Sixteen soil cores were taken from both ridges and furrows (Leistra and Boesten 2008). Core sections of $0.1 \mathrm{~m}$ were analyzed separately for bromide ion, so there were 16 analyses per sampling date and depth (for both ridges and furrows). Soil bulk density and moisture content were also measured for each sample. The four samples per depth in a field quarter were pooled to form one sample for analysis of carbofuran. So the insecticide was measured in quadruplicate for each sampling time and depth (for both ridges and furrows). In some cases, two adjacent $0.1 \mathrm{~m}$ sections from the subsoil were combined into one $0.2 \mathrm{~m}$ section.

Bromide ion was extracted by shaking $45 \mathrm{~g}$ moist soil with $40 \mathrm{ml}$ water for $1 \mathrm{~h}$. A subsample of the supernatant water layer was filtered $(0.45 \mu \mathrm{m})$ and subjected to highperformance liquid chromatography (HPLC) $\left(20^{\circ} \mathrm{C}\right)$ using an anion-exchange column. The octadecyl silane C18 column (250 mm long, $4.6 \mathrm{~mm}$ inner diameter, Hypersil ODS; Thermo Quest) was loaded with tetrabutylammonium dihydrogen phosphate as an anion exchanger. The mobile phase was an aqueous solution of 0.004 mol tetrabutylammonium dihydrogen phosphate per 1 and $0.005 \mathrm{~mol}$ phosphate buffer $\left(\mathrm{KH}_{2} \mathrm{PO}_{4}\right.$ and $\left.\mathrm{Na}_{2} \mathrm{HPO}_{4} \cdot \mathrm{H}_{2} \mathrm{O}\right)$ per l. It was pumped (Spectroflow 400; Separations) through the column at a flow rate of $1.5 \mathrm{ml} \mathrm{min}{ }^{-1}$. A volume of $200 \mu \mathrm{l}$ of the bromide extract was injected by autosampler (Marathon; Spark Holland). Bromide ion was measured by spectrophotometric ultraviolet (UV) detection (Spectroflow 757; Separations) at wavelength of $210 \mathrm{~nm}$. The efficiency of extraction from soil was $93 \%$; the results were not corrected for this. The limit of quantification in soil was $0.4 \mathrm{mg} \mathrm{kg}^{-1}$.

Carbofuran was extracted by shaking $100 \mathrm{~g}$ moist soil sample with $100 \mathrm{ml}$ methanol for $1 \mathrm{~h}$. The extracts were analyzed by HPLC using a reversed-phase column
(150 mm long, $3.9 \mathrm{~mm}$ inner diameter, Novapak C18; Novapak) at $40^{\circ} \mathrm{C}$. The mobile phase consisted of acetonitrile/water (volume ratio 30/70), pumped (Waters 590 pump; Waters) at flow rate of $1 \mathrm{ml} \mathrm{min}^{-1}$ through the column. Dependent on the expected concentration level, 20-100 $\mu \mathrm{l}$ was injected by autosampler (ISS 100; Perkin Elmer). A spectrophotometric detector (LC 90 UV; Perkin Elmer) was used to measure carbofuran at wavelength of $230 \mathrm{~nm}$. The recovery of carbofuran from topsoil material was measured on average at $98 \%$, and that from subsoil material on average at $85 \%$; the results were not corrected for this. The limit of quantification in soil was shown to be $0.8 \mu \mathrm{g} \mathrm{kg}^{-1}$. Shortly after spraying the substances, soil cores were taken to a depth of $0.20 \mathrm{~m}$. The initial amounts of both bromide ion and carbofuran in soil were measured to be $106 \%$ of the calculated dosage.

\section{Setup of the Computations}

Chemical transport processes in the ridge and furrow systems of the potato field were simulated by using the PEARL model, version 3.3.3. The model was coupled to the soil-water-atmosphere-plant (SWAP) model for description of the hydrologic processes (van Dam et al. 1997). Concise descriptions of the PEARL-SWAP combination of models are presented in two studies of the risk of pesticide leaching from soils (Boesten 2004, 2007). In short, the SWAP model describes uniform water flow in the soil system using Richards' equation, and the transport of substances in the soil system is described by PEARL using the convection-dispersion equation (Leistra et al. 2001; Tiktak et al. 2000). The ridge and furrow systems were schematized as shown in Fig. 2. To simulate the build-up

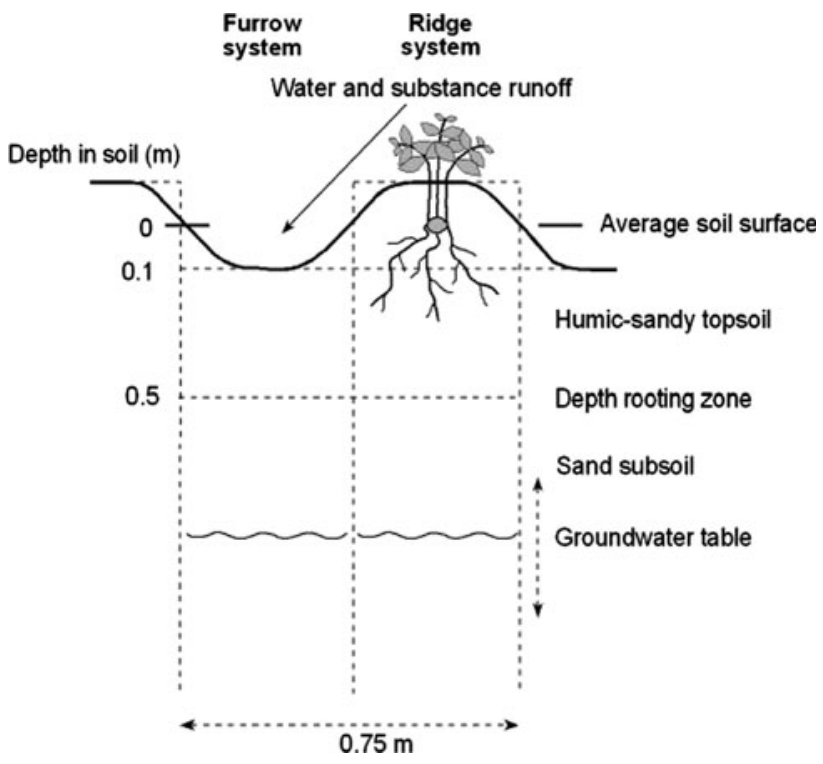

Fig. 2 Schematization of the ridge and furrow systems 
of ridges with furrow material, the top $0.1 \mathrm{~m}$ of the field soil was removed from the furrow system and added to the ridge system. Thus the humic-sandy top layer of the ridge system was $0.2 \mathrm{~m}$ thicker than that of the furrow system. Based on relief measurements of the soil surface, it was assumed that the ridge and furrow systems each accounted for half of the surface area of the field.

In a field with ridges and furrows, some of the water from rainfall and sprinkler irrigation can flow down the sides of the ridges to the furrows. Preliminary computations (Leistra and Boesten 2008) indicated that about 20\% of the rainfall plus irrigation falling on the ridges did so. This runoff seemed to be restricted to the first month after application of the substances, before and just after the potato plants emerged. In the calculations, $20 \%$ runoff in the first month was obtained by multiplying the measured rainfall plus irrigation by 0.8 for the ridge system and by 1.2 for the furrow system. Part of the substances sprayed on the soil surface can be expected to be transported from the ridges to the furrows via the runoff. On the first measuring dates (when leaching had not yet occurred), there were larger amounts of the substances in the furrow soil than in the ridge soil (Leistra and Boesten 2008). Using the measured data, the extent of substance runoff from the ridges was estimated to be $15 \%$ of the dosage. Assuming that this movement occurred soon after the substances had been applied, in the computations the field-averaged dosage was decreased by $15 \%$ for the ridge system and increased by $15 \%$ for the furrow system.

The soil systems were simulated to a depth of $3 \mathrm{~m}$ in the field. The computation compartments were $0.02 \mathrm{~m}$ thick. The properties of each soil horizon of $0.1 \mathrm{~m}$ thickness were derived by interpolating and extrapolating the data measured for the Roswinkel field (Table 1). The dispersion length for the spreading of substance during transport with water was set at $0.05 \mathrm{~m}$. Substance diffusion in the water and gas phases was described by Currie's method. Daily minimum and maximum air temperatures were inputted into the model for the calculation of soil temperatures. The depth factor $f_{z}$ for the effect of soil depth on pesticide transformation rate was taken from the Dutch standard scenario (Boesten and van der Linden 1991). The simulation of water flow in the Roswinkel soil was based on hydraulic relationships presented for a similar topsoil and subsoil (Wösten et al. 2001). These relationships were calibrated visually against the measured soil moisture profiles, averaged for the whole Roswinkel field (Leistra and Boesten 2008). The depth of the water table (which fluctuated between 0.9 and $1.3 \mathrm{~m}$ in the growing period) was introduced as a function of time on the basis of the measurements.

The development of the potato crop on the Roswinkel field was defined by using the "fixed crop cycle" option in
PEARL (Tiktak et al. 2000). The plants emerged on the ridge system on 22 May 2000, and canopy cover on the ridges was taken to increase linearly until full cover on 20 June. Rooting depth was taken to increase linearly from $0.2 \mathrm{~m}$ on 22 May to the final depth of $0.6 \mathrm{~m}$ in the ridge system on 10 July. It takes some time for the roots of the potato plants in the ridges to reach the soil under the furrows (Fig. 2), so root development and water uptake in the furrows were assumed to start on 10 June 2000, at zero depth. From this date onwards, a potato crop was assigned to the furrow system, with the canopy cover increasing linearly from zero (10 June) to full cover (10 July). In the furrow system, the maximum rooting depth of $0.4 \mathrm{~m}$ was assumed to be reached on 10 July. In the top half of the rooting zone, root activity was taken to be constant with depth; in the lower half it decreased linearly with depth to zero at the bottom of the rooting zone (Pinto 1988; Gregory and Simmonds 1992). Water uptake by plant roots at a certain depth in soil was dependent on the pressure head of the water at that depth, as specified for a potato crop (van Dam et al. 1997).

A fully grown potato crop was simulated to be present in the period 10 July to 18 September 2000. In this period, the height of the crop was taken to be $0.5 \mathrm{~m}$ and its leaf area index was set at 4 (Feddes 1987; Pinto 1988). The potential transpiration by the potato crop (ample water supply) was calculated by multiplying the reference crop evaporation (KNMI 2000) by a crop factor of 1.1 (Feddes 1987). The potential soil evaporation (from a wet soil surface) was set equal to the reference crop evaporation. The leaf area index of the crop determines the contributions of the plant and soil terms to the overall potential evapotranspiration. Plant transpiration decreases when moisture in the root zone of the soil becomes depleted, while soil evaporation decreases when the soil surface dries. Details on the computation of plant transpiration and soil evaporation are given by van Dam et al. (1997) and Leistra et al. (2001). In the period from 19 September to 16 October, the foliage died off linearly until no active canopy remained. The soil was kept bare during the next year (2001).

\section{Input Data for the Substances}

Bromide ion was selected as a tracer for water flow because it barely interacts with soil. The ionic mass of bromide ion is $79.9 \mathrm{~g} \mathrm{~mol}^{-1}$. The vapor pressure of bromide ion was set to zero and its solubility in water at $10^{5} \mathrm{mg} \mathrm{l}^{-1}$ (an arbitrary high value). The coefficient for diffusion of bromide ion in water (Lide 1999), translated to $20^{\circ} \mathrm{C}$, was taken to be $1.610^{-4} \mathrm{~m}^{2} \mathrm{day}^{-1}$. Adsorption of bromide ion to soil was set to zero. The half-life of transformation in soil was taken to be $10^{5}$ days (an arbitrary high value) at $20^{\circ} \mathrm{C}$. The concept of the transpiration stream concentration factor 
(TSCF) for uptake by plant roots (Briggs et al. 1982) does not hold for ionic species. As there is no alternative in the model and as no quantitative information was available, the TSCF was set at 0.5 .

Physical properties of carbofuran collected from the literature are presented in Table 2 . The values stated for the vapor pressure range from moderate to low values, so a compromise value of $0.1 \mathrm{mPa}$ at $20^{\circ} \mathrm{C}$ was used as input for the computations. Solubility in water (input value $320 \mathrm{mg} \mathrm{l}^{-1}$ at $20^{\circ} \mathrm{C}$ ) and octanol/water partitioning indicate intermediate polarity of carbofuran molecules. The coefficient for diffusion of carbofuran in air at the reference temperature $\left(20^{\circ} \mathrm{C}\right)$ was estimated to be $0.44 \mathrm{~m}^{2}$ day $^{-1}$, using the Fuller, Schettler and Giddings (FSG) method (Tucker and Nelken 1982). Using the method of Hayduk and Laudie (Tucker and Nelken 1982), the diffusion coefficient of carbofuran in water was estimated to be $0.44 \times 10^{-4} \mathrm{~m}^{2} \mathrm{day}^{-1}$.

Adsorption of carbofuran to Roswinkel topsoil (at $15^{\circ} \mathrm{C}$ ) was measured in triplicate, at each of four concentrations in solution (Leistra and Boesten 2008). Soil (43 g on dry mass basis) and carbofuran solution $(57 \mathrm{ml})$ in centrifuge tubes were slowly rotated on an inclined disk for $24 \mathrm{~h}$. After this, the tubes were centrifuged at $33 \mathrm{~s}^{-1}(600 \mathrm{~g})$ for $20 \mathrm{~min}$. The concentrations of carbofuran left in solution (range $0.003-0.23 \mathrm{mg} \mathrm{l}^{-1}$ ) were measured by HPLC, as described for the soil extracts. The Freundlich coefficient $K_{\mathrm{F}}$ (at $15^{\circ} \mathrm{C}$ ) was measured to be $0.771 \mathrm{~kg}^{-1}$, and the exponent was 0.83 . The value of the coefficient $K_{\text {om }}$ for the adsorption of carbofuran to soil organic matter was calculated to be $16 \mathrm{l} \mathrm{kg}^{-1}$. This value indicates that the adsorption of carbofuran to soils is moderate to weak.

The rate of transformation of carbofuran in the Roswinkel soil had to be estimated from measurements in the field. The half-life for the decline of carbofuran in the soil in the growing season was calculated to be 31 days (Leistra and Boesten 2008). Preliminary computations indicated that there was hardly any volatilization, that the contribution of uptake by the plant roots to the decline was small, and that little leaching occurred in the growing season. So the half-life for the transformation of carbofuran in Roswinkel topsoil ( $\mathrm{pF} 2,15^{\circ} \mathrm{C}$ ) was set to 35 days. Uptake of carbofuran by roots of the potato crop was described according to Briggs et al. (1982). They derived a relationship between the transpiration stream concentration factor (TSCF) and the $\log \left(P_{\text {ow }}\right)$ value for octanol/water partitioning of the compound. Using this relationship, the TSCF value for carbofuran was calculated to be 0.78 (potentially high uptake).

\section{Results and Discussion}

\section{Water Flow}

The amount of water taken up by the crop in the growing period was calculated to be $261 \mathrm{~mm}$ for the ridge system and $208 \mathrm{~mm}$ for the furrow system. These amounts were equal to potential transpiration, which indicates that there was no water shortage. Evaporation from the soil surface in the period from 10 May to 16 October 2000 was calculated to be $119 \mathrm{~mm}$ for the ridges and $157 \mathrm{~mm}$ for the furrows. The amount of water percolating through the ridge system to the subsoil was calculated to be $157 \mathrm{~mm}$, compared with $248 \mathrm{~mm}$ for the furrow system. Thus the differences between the items of the water balance calculated for the ridge and furrow systems were substantial.

\section{Movement of Bromide Ions}

Fig. 3 shows the measured and computed concentrations of bromide ion in the soil of the ridge and furrow systems on the three sampling dates. On 29 May 2000, the distribution of bromide (measured and computed) was still present in the top $1 \mathrm{~m}$ of the soil profile. Both the measurements and the computations showed that downward movement of bromide ion was distinctly greater in the furrow system than in the ridge system, presumably because of water flowing off the ridges to the furrows, where it infiltrated. At the first sampling date, the peak of the bromide distribution was measured to be in the $0.1-0.2 \mathrm{~m}$ layer of the ridges,
Table 2 Physical properties of carbofuran, obtained from the literature

\begin{tabular}{lll}
\hline Property & Value, unit, condition & Reference \\
\hline Molar mass & $221.3 \mathrm{~g} \mathrm{~mol}^{-1}$ & (Tomlin 2003) \\
Vapor pressure & $0.031 \mathrm{mPa}$ at $20^{\circ} \mathrm{C}$ & (Tomlin 2003) \\
& $0.072 \mathrm{mPa}$ at $20^{\circ} \mathrm{C}$ & \\
& $0.23 \mathrm{mPa}$ at $20^{\circ} \mathrm{C}$ & (EU 2007) \\
& $0.08 \mathrm{mPa}$ at $25^{\circ} \mathrm{C}$ & \\
Solubility in water & $320-351 \mathrm{mg}^{-1}\left(20^{\circ} \mathrm{C}\right)$ & (Tomlin 2003) \\
& $315-322 \mathrm{mg} \mathrm{l}^{-1}\left(20^{\circ} \mathrm{C}\right)$ & (EU 2007) \\
Octanol/water partitioning & $\log \left(P_{\mathrm{ow}}\right)=1.52\left(20^{\circ} \mathrm{C}\right)$ & (Tomlin 2003) \\
& $\log \left(P_{\mathrm{ow}}\right)=1.8\left(20^{\circ} \mathrm{C}\right) ; 1.62\left(22^{\circ} \mathrm{C}\right)$ & (EU 2007) \\
\hline
\end{tabular}


Fig. 3 Measured and computed concentrations of bromide ion in the soil of the ridge (R) and furrow $(\mathrm{F})$ systems on the three sampling dates. Closed symbols measuring points; dashed line average of measuring points; dashed line with open symbols computed
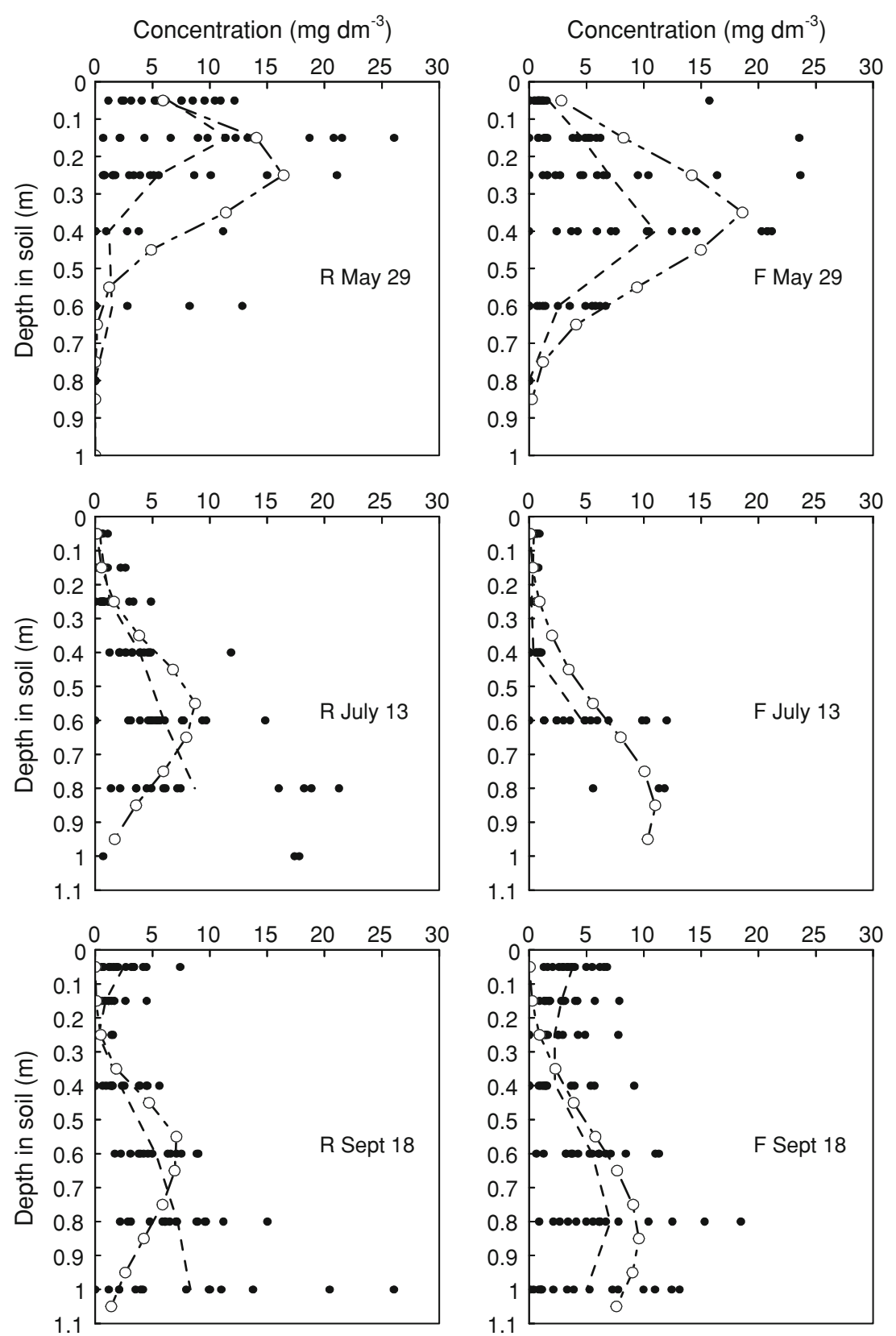

while it was in the $0.3-0.5 \mathrm{~m}$ layer of the furrows. On 13 July, bromide ion had moved deeper, some of it to more than $1 \mathrm{~m}$ depth in the soil. Unfortunately, it was difficult to retain the wet subsoil samples in the cores, and several deeper samples were lost. Nevertheless, the movement of bromide ion measured in the furrow system still tended to be greater than that in the ridge system. On the last sampling date (18 September), both the measurements and computations revealed that there had been little further downward movement of bromide ion in the soil profile since 13 July.

On the first sampling date (29 May 2000), the amount of bromide ion measured in the soil profiles (Fig. 3) was only
$53 \%$ of the dosage. Possibly, a (small) fraction of the bromide dosage had leached below the sampling depth. The main cause of the low amount may be that, even though 16 cores were taken from both the ridges and furrows, higher concentrations in the soil were missed because of the wide variation of bromide concentration in the soil profiles. Ghodrati and Jury (1990) and Flury (1996) illustrated the problem of representative sampling of heterogeneous substance distributions in soil. On 13 July, only a limited number of soil samples could be collected from the subsoil at $0.8 \mathrm{~m}$ and deeper, especially from below the furrows, because the wet subsoil material slipped off the corer. On 18 September, sampling of the subsoil was more 
successful, resulting in more measured concentrations. Bromide ion concentration increased in the top layer of the soil between 13 July and 18 September. Bromide ion is taken up via the root system to vital plant parts and then released from senescent plant parts to the topsoil later in the growing season (Kung 1990a).

At each depth, there was a wide range in the measured concentration of bromide ion (Fig. 3), which is an indication of preferential transport due to soil heterogeneity. This raises the question of whether the average distribution of bromide ion with soil depth can be described using a dispersion coefficient in a chromatographic transport model. The movement of bromide ions in the ridge soil measured in July and September was, on average, deeper than the movement computed with the model, confirming that preferential flow and transport occurred in the ridge soil. For the furrows, movement measured in July tended to be greater than computed movement, but rigorous comparison was hampered by the small number of measurements from deeper soil. The movement of bromide measured in the furrow soil in September was only slightly greater than that computed. It is possible that stem flow induced more preferential flow and transport in the ridge soil than in the furrow soil.

The amount of bromide ion computed to be taken up by the crop from the ridge system corresponded to $35 \%$ of the net dosage on the ridges (gross dosage minus surface transport). In the furrow system, $3.9 \%$ of the final dosage (field dosage plus surface transport) was computed to be taken up by the crop. In the latter case, the vast majority of the bromide wave moved ahead of the developing root system.

\section{Movement of Carbofuran}

The results of the measurements and computations for carbofuran in the ridge and furrow soil systems are shown in Fig. 4. On the first date (29 May 2000), though carbofuran was still present in the upper part of the soil profiles, it had moved deeper in the furrow system than in the ridge system. This is related to the surface flow of water (rainfall plus sprinkler irrigation) from the ridges to the furrows. On 13 July, the peak of the carbofuran distribution was still in the top $0.1 \mathrm{~m}$ layer of the ridges, while the pesticide was rather evenly distributed in the top $0.6 \mathrm{~m}$ of the furrows. The results for September show a further evening-out of the carbofuran distribution in the soil profiles, with higher concentrations in the lower half for the furrow soil than for the ridge soil (both measured and computed).

On 29 May 2000, the computed amount of carbofuran in the soil profiles was distinctly smaller than that measured (Fig. 4). The model assumed first-order transformation kinetics, with a rate coefficient derived from the amounts measured in the entire potato growing period. In the field, the transformation of carbofuran was initially slow (a kind of lag phase) (Leistra and Boesten 2008). On the second and third comparison dates, the amounts of carbofuran measured in the soil systems corresponded better to the first-order transformation kinetics for the entire period. In July and September 2000, the concentrations of carbofuran measured in the top of the ridge systems were higher than the computed concentrations (Fig. 4), indicating that some of the carbofuran in soil was outside the main flow paths of the water. The phenomenon was less clear for the furrow soil.

The concentrations of carbofuran measured at the sampling depths show substantial variation (Fig. 4). Each measuring point was obtained for a composite of four subsamples, which will have reduced the variation as compared with that for bromide ion. The wide variation in concentration per depth indicates that preferential transport of carbofuran occurred in the soil systems, due to soil heterogeneity. Carbofuran in the infiltrated water can be expected to give the highest concentrations in the soil with the preferential flow paths. The incidental higher concentrations deeper in the soil systems, especially in the furrow systems, indicate that a distinct amount of carbofuran leached to depths below $1 \mathrm{~m}$ via preferential flow paths.

The amount of carbofuran transformed in the ridge soil in the period from 10 May (application) to 16 October 2000 (end of growing season) was computed to be $83.9 \%$ of the net dosage on the ridges (field dosage minus surface transport). Uptake by plant roots in the ridge system was computed to be $12.7 \%$ of the dosage in this period. Volatilization from soil was computed to be nil. At the end of the growing season (16 October), 3.4\% of the dosage was computed to remain in the soil profile, all in the top $1 \mathrm{~m}$. In the furrow system, $87.8 \%$ of the dosage on the furrows (field dosage plus surface transport) was computed to be transformed in the soil in the period from 10 May to 16 October 2000. For this system, uptake by plant roots was computed to be $5.9 \%$ of the dosage. On 16 October, $6.4 \%$ of the dosage was computed to remain in the soil of the furrow system, and movement below $1 \mathrm{~m}$ depth $(0.5 \%$ of the dosage) had started in the simulation.

\section{Discussion}

The results revealed that movement of the substances in the furrow soil was greater than that in the ridge soil. This confirms that some of the precipitation water (rainfall plus sprinkler irrigation) can flow off the ridges to the furrows, resulting in more infiltration in the latter (Robinson 1999; Starr et al. 2005). In the present study, this flow-off seemed to occur before crop emergence and in the presence of a 
Fig. 4 Measured and computed concentrations of carbofuran in the soil of the ridge (R) and furrow $(\mathrm{F})$ systems on the three sampling dates. Closed symbols measuring points; dashed line average of measuring points; dashed line with open symbols computed. Note the difference in horizontal scale for the three dates
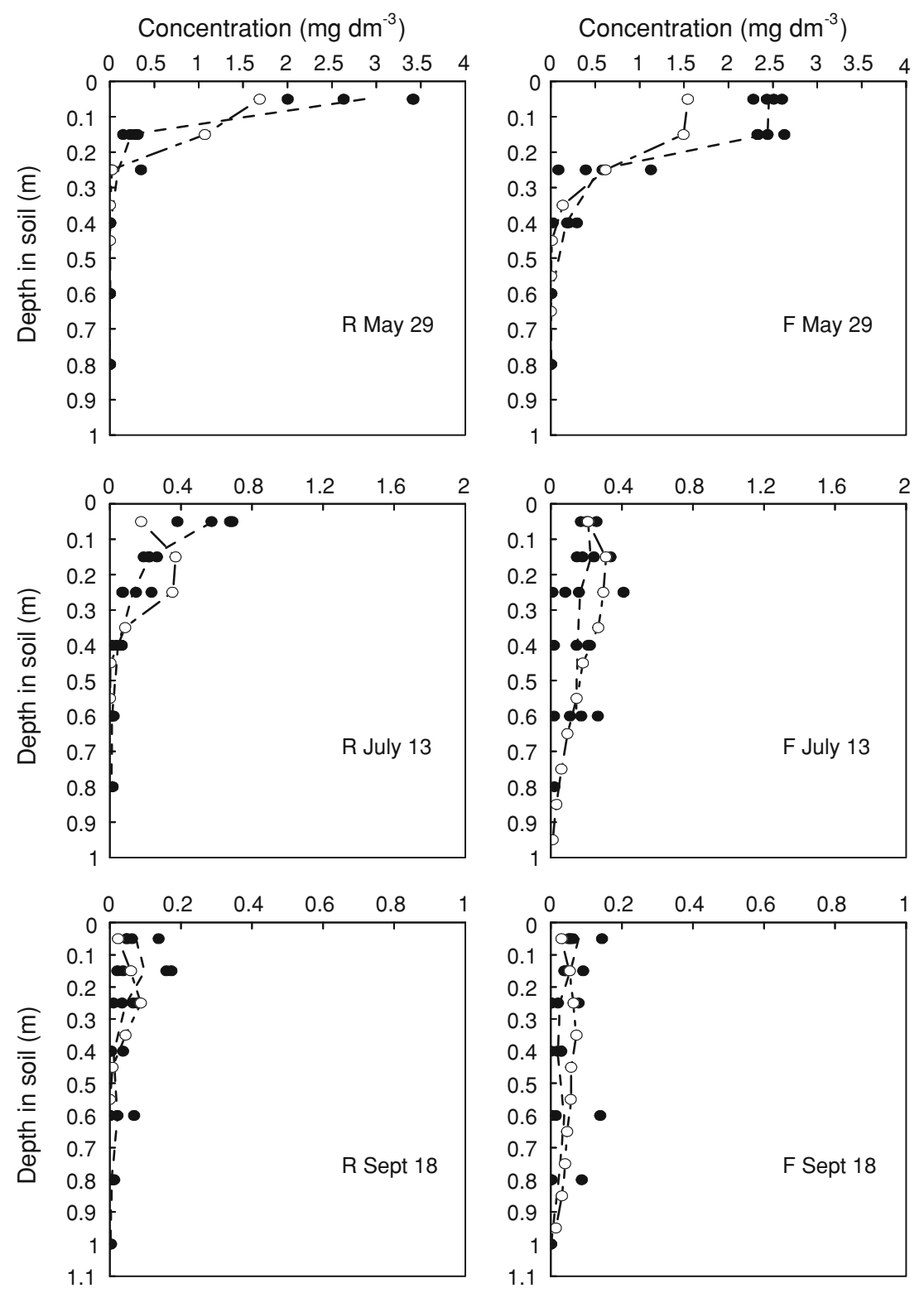

young crop, i.e., when the soil was mostly bare. In the computations, it was assumed that $20 \%$ of the precipitation water flowed off the ridges to the furrows in the first month after application of the substances. This could roughly explain the greater movement of the substances in the furrow system, as compared with that in the ridge system.

The presence of a well-developed crop canopy can be expected to greatly affect the pattern of water infiltration into the soil. The intercepted precipitation water will follow certain flow pathways through the canopy, e.g., down stems and off leaves (Jefferies and MacKennon 1985). The pattern of water infiltration in soil could vary over time due to changes in crop development, intensity and duration of rainfall, wind direction and speed, soil surface condition, etc. The finding that a large part of the bromide ions had moved out of the top layer in July (Fig. 3) shows that the canopy's shielding of the soil surface from precipitation is variable. By contrast, more carbofuran was measured to be retained in the top layer of the ridges in July and September than was computed (Fig. 4). This could be the result of slow desorption and release from the sorption surfaces in the finest pores.

The wide variation found in the concentration of the substances at the measuring depths was presumably caused by preferential water flow and substance transport. These phenomena are now known to be much more common in sandy soils than was assumed before the 1990s. Complicated patterns of preferential flow paths in sandy soil, induced by rainfall and sprinkler irrigation, were visualized using dyes (van Ommen et al. 1989a; Kung 1990b). Wide variation in the concentration of bromide ion at various depths in sandy soils was also measured by van Ommen 
et al. (1989b) and Ritsema and Dekker (1995). In chromatographic transport models, small-scale heterogeneities in transport are accounted for by using a dispersion coefficient. The transport is then simulated to occur as a wave through the soil profile, which widens with depth. The measured movement of bromide ions in soil was faster than simulated by the model, particularly for the ridge system. Average downward movement of carbofuran was described reasonably well by the model. However, locally higher concentrations indicate that preferential transport of carbofuran occurred. So the results confirm the occurrence of fast preferential substance transport in sandy soil.

Our findings demonstrate that, in fields with ridges and furrows, there is an increased risk of leaching of pesticide residues to depths below $1 \mathrm{~m}$ in soil. Water and pesticide can flow off the ridges to the furrows, leading to increased water infiltration and pesticide loading in the latter. Because topsoil material has been removed to create the ridges, the furrows have a thinner rooting zone, especially when there is a dense sandy subsoil. In general, root activity is often later and less in the furrow soil than in the ridge soil, so there is less water and pesticide uptake in the former. Due to the faster transport in the furrow soil, it is likely that there will be less time for transformation of the pesticide there than in the ridges. Thus a combination of factors can cause leaching from furrow soil to be greater than that from ridge soil. For the same reasons, leaching from furrow soil can be greater than that from a more level field without ridges and furrows.

Acknowledgment This work was carried out within the framework of Research Theme BO-06-10: "Risk assessment methodology for pesticide registration" of the Dutch Ministry of Agriculture, Nature, and Food Quality.

Open Access This article is distributed under the terms of the Creative Commons Attribution Noncommercial License which permits any noncommercial use, distribution, and reproduction in any medium, provided the original author(s) and source are credited.

\section{References}

Boesten JJTI (2004) Influence of dispersion length on leaching calculated with PEARL, PELMO and PRZM for FOCUS groundwater scenarios. Pest Manage Sci 60:971-980

Boesten JJTI (2007) Simulation of pesticide leaching in the field and in zero-tension lysimeters. Vadose Zone J 6:793-804

Boesten JJTI, van der Linden AMA (1991) Modeling the influence of sorption and transformation on pesticide leaching and persistence. J Environ Qual 20:425-435

Briggs GG, Bromilow RH, Evans AA (1982) Relationships between lipophilicity and root uptake and translocation of non-ionised chemicals by barley. Pestic Sci 13:495-504

Butters GL, Benjamin JG, Ahuja LR, Ruan H (2000) Bromide and atrazine leaching in furrow- and sprinkler-irrigated corn. Soil Sci Soc Am J 64:1723-1732
CBS (2009) Agriculture; crops, animals, land use. http://statline. cbs.nl/statweb. CBS Statistics Netherlands, The Hague/Heerlen

Cooley ET, Lowery B, Kelling KA, Wilner S (2007) Water dynamics in drip and overhead sprinkler irrigated potato hills and development of dry zones. Hydrol Process 21:2390-2399

Dekker LW, Ritsema CJ, Oostindie K, Wendroth O, Pohl W, Jarvis NJ, Larsson MH, Gaudet JP (1999) Moisture distributions and wetting rates of soils at experimental fields in the Netherlands, France, Sweden and Germany. J Hydrol 215:4-22

EU (2007) Review report for the active substance carbofuran. SANCO/ 10054/2006 final. 7 September 2007. European Commission, Brussels. http://europa.eu.int/comm/food/plant/protection/evaluation/ index_en.htm

Eurostat (2009) Agricultural products. http://epp.eurostat.ec.europa.eu/ portal/page/portal/agriculture/data/main_tables. Eurostat, European Commission, Brussels

FAO (1988) FAO-UNESCO soil map of the world. Revised legend. World resources report 60. Food and Agriculture Organization of the United Nations, Rome, Italy

Feddes RA (1987) Crop factors in relation to Makkink reference-crop evapotranspiration. In: Hooghart JC (ed) Evaporation and weather. Proceedings and information 39. TNO Committee on Hydrological Research, The Hague, The Netherlands, pp 33-45

Flury M (1996) Experimental evidence of transport of pesticides through field soils-a review. J Environ Qual 25:25-45

FOCUS (2000) FOCUS groundwater scenarios in the EU review of active substances. Report of the FOCUS Groundwater Scenarios Workgroup. EC Document Reference Sanco/321/2000 rev. 2, 202 pages. European Commission, Brussels

Ghodrati M, Jury WA (1990) A field study using dyes to characterize preferential flow of water. Soil Sci Soc Am J 54:1558-1563

Gregory PJ, Simmonds LP (1992) Water relations and growth of potatoes. In: Harris P (ed) The potato crop. The scientific basis for improvement. Chapman and Hall, London, pp 214-246

Jefferies RA, MacKennon (1985) Stemflow in potato crops. J Agric Sci 105:205-207

KNMI (2000) Maandoverzicht neerslag en verdamping in Nederland (Monthly survey of precipitation and evaporation in The Netherlands). Royal Netherlands Meteorological Institute, De Bilt, The Netherlands

Kung KJS (1990a) Influence of plant uptake on the performance of bromide tracer. Soil Sci Soc Am J 54:975-979

Kung KJS (1990b) Preferential flow in a sandy vadose zone. 2. Mechanisms and implications. Geoderma 46:59-71

Leistra M, Boesten JJTI (2008) Movement of bromide-ion and carbofuran in the humic sandy soil of a potato field with ridges and furrows. Measurements in the field and computations with the PEARL model. Alterra-rapport 1750, Alterra, Wageningen University and Research Centre, Wageningen, The Netherlands

Leistra M, van der Linden AMA, Boesten JJTI, Tiktak A, van den Berg $F(2001)$. PEARL model for pesticide behaviour and emissions in soil-plant systems. Description of the processes in FOCUS PEARL v 1.1.1. Alterra-rapport 013; RIVM report 711401009. Alterra, Green World Research, Wageningen, The Netherlands. www.alterra.wur.nl/UK/publications/Alterra+Reports/

Lide DR (ed) (1999) CRC handbook of chemistry and physics, 80th edn. CRC, Boca Raton FL, USA

Pinto PJCA (1988) Computer simulation modeling of the growth and development of the potato crop under different water regimes. $\mathrm{PhD}$ Dissertation, University of California, Davis, CA

Ritsema CJ, Dekker LW (1995) Distribution flow: a general process in the top layer of water repellent soils. Water Resour Res 31:1185-1200

Robinson D (1999) A comparison of soil-water distribution under ridge and bed cultivated potatoes. Agric Water Manage 42:189-204 
Saffigna PG, Tanner CB, Keeney DR (1976) Non-uniform infiltration under potato canopies caused by interception, stemflow and hilling. Agron J 68:337-342

Smelt JH, Schut CJ, Dekker A, Leistra M (1981) Movement and conversion of aldicarb and its oxidation products in potato fields. Neth J Plant Pathol 87:177-191

Starr GC, Cooley ET, Lowery B, Kelling K (2005) Soil water fluctuations in a loamy sand under irrigated potato. Soil Sci 170:77-89

Tiktak A, van den Berg F, Boesten JJTI, van Kraalingen D, Leistra M, van der Linden AMA (2000) Manual of FOCUS PEARL version 1.1.1. RIVM report 711401008 , Alterra report 28. National Institute of Public Health and the Environment: Bilthoven, The Netherlands. www.alterra.wur.nl/UK/publications/Alterra+Reports/

Tomlin CDS (2003) The pesticide manual. A world compendium, 13th edn. British Crop Protection Council, Alton, Hampshire, UK

Tucker WA, Nelken LH (1982) Diffusion coefficients in air and water. In: Lyman WJ, Reehl WF, Rosenblatt DH (eds) Handbook of chemical property estimation methods. Environmental behavior of organic compounds. McGraw-Hill, New York, pp 1-25

van Dam JC, Huygen J, Wesseling JG, Feddes RA, Kabat P, van Walsum PEW, Groenendijk P, van Diepen CA (1997) SWAP version 2.0. Theory. Simulation of water flow, solute transport and plant growth in the soil-water-atmosphere-plant environment. Report 71, Department of Water Resources, Wageningen Agricultural University, Wageningen, The Netherlands

van Ommen HC, Dijksma R, Hendrickx JHM, Dekker LW, Hulshof J, van den Heuvel M (1989a) Experimental assessment of preferential flow paths in a field soil. J Hydrol 105:253-262

van Ommen HC, van Genuchten MTh, van der Molen WH, Dijksma R, Hulshof J (1989b) Experimental and theoretical analysis of solute transport from a diffuse source of pollution. J Hydrol 105:225-251

Waddell JT, Weil RR (2006) Effects of fertilizer placement on solute leaching under ridge tillage and no tillage. Soil Tillage Res 90:194-204

Wösten JHM, Veerman GJ, de Groot WJM, Stolte J (2001) Waterretentieen doorlatendheidskarakteristieken van boven- en ondergronden in Nederland: de Staringreeks (Water retention and conductivity characteristics of topsoils and subsoils in The Netherlands: the Staring Series). Alterra Rapport 153, Alterra, Wageningen, The Netherlands. www.alterra.wur.n1/UK/publications/Alterra+ Reports/

Wyman JA, Jensen JO, Curwen D, Jones RL, Marquardt TE (1985) Effects of application procedures and irrigation on degradation and movement of aldicarb residues in soil. Environ Toxicol Chem 4:641-651 